\title{
Biodegradation of Oil Shale by Phanerochaete chrysosporium
}

\author{
Wenxing Wang ${ }^{1, ~ a, ~ S h a o y a n ~ J i a n g ~}{ }^{2, b}$ and Lanshu $\mathrm{Li}^{1, \mathrm{c}}$ \\ ${ }^{1}$ College of Life \& Health Sciences, Northeastern University, Shenyang 110169, China \\ ${ }^{2}$ School of Materials \& Metallurgy, Northeastern University, Shenyang 110819, China \\ awangwenxing@126.com, biangshao_1@163.com, '862052820@qq.com
}

Keywords: Oil shale, Phanerochaete chrysosporium, Biodegradation, Culture conditions

Abstract. Effect of culture conditions on biodegradation of oil shale by Phanerochaete chrysosporium was studied. XRD and FT-IR were used to analyze oil shale before and after nitric acid pretreatment, degradation residues, and degradation products. The results showed that $15 \mathrm{~d}$ of degradation time, high carbon-nitrogen ratio of culture medium, and $32^{\circ} \mathrm{C}$ of degradation temperature were conductive to increasing the degradation rate of oil shale. XRD analysis indicated that silicate components of oil shale pretreated with nitric acid could be partially degraded by P. chrysosporium. FT-IR analysis showed that most of degradation products were aromatic hydrocarbons and a small amount of aliphatic hydrocarbons.

\section{Introduction}

Oil shale, known as an unconventional oil and gas resource, is an organic-rich sedimentary rock containing kerogen with complicated three-dimensional network structure [1]. In recent years, the advantages of microbial metallurgy have been highlighted, such as simple technical process, low-carbon and environmentally friendly operation, low energy consumption, and low costs [2]. Oil shale was confirmed to provide the sole carbon source and energy for the growth of individual or mixed bacterial strains accompanying structural changes of oil shale [3-5]. In addition, mixed strains (Rhodococcus erythropolis and Rhodococcus ruber) that produce biosurfactants were used to degrade the organic matter in oil shale, indicating that the maximum extracting ratio of shale oil was up to $26 \%$ [6]. While some studies have confirmed the degradation of oil shale by bacteria, little research has been done in it by fungi. Just the biotransformation of oil shale by the fungus Schizophyllum commune has been reported that the organic matter in oil shale can be decomposed and released to the surroundings [7]. The fungus Phanerochaete chrysosporium have the system of ligninolytic enzymes that can degrade many complex macromolecular organic matters like lignocellulose.

In this work, we attempted to investigate the degradation of oil shale by Phanerochaete chrysosporium as well as the effect of culture conditions and the analysis of degradation products. This work will provide a useful reference for further studies of oil-shale bio-utilization and eco-environmental protection of mines.

\section{Materials and Methods}

Materials. The used fungus was Phanerochaete chrysosporium (P. chrysosporium). The oil shale was obtained from Fushun West Open Pit, China. All the chemicals with analytical grade were purchased from National Medicines Corporation Ltd., China.

Pretreatment of Oil Shale Samples. $75 \mu \mathrm{m}$ of oil shale samples were obtained after crushing, grinding and screening. All the samples were dipped into $5 \mathrm{~mol} \cdot \mathrm{L}^{-1} \mathrm{HNO}_{3}$ for $2 \mathrm{~d}$, rinsed with diluted water until close to neutral, sterilized with high-pressure steam, and then dried with an oven at $60^{\circ} \mathrm{C}$ for use.

Culture Media. Liquid potatodextrose medium contained (per liter of distilled water) $200 \mathrm{~g}$ of potato extract and $20 \mathrm{~g}$ of glucose. Nitrogen-limited medium contained (per liter of distilled water) $0.37 \mathrm{~g}$ of ammonium tartrate, $10 \mathrm{~g}$ of glucose, $4.0 \mathrm{~g}$ of $\mathrm{KH}_{2} \mathrm{PO}_{4}, 1.0 \mathrm{~g}$ of $\mathrm{MgSO}_{4} \cdot 7 \mathrm{H}_{2} \mathrm{O}, 0.05 \mathrm{~g}$ of $\mathrm{CaCl}_{2}$, 
and $4 \mathrm{mg}$ of Vitamin $\mathrm{B}_{1}$. Carbon- limited medium contained (per liter of distilled water) $4.44 \mathrm{~g}$ of ammonium tartrate, $2 \mathrm{~g}$ of glucose, $4.0 \mathrm{~g}$ of $\mathrm{KH}_{2} \mathrm{PO}_{4}, 1.0 \mathrm{~g}$ of $\mathrm{MgSO}_{4} \cdot 7 \mathrm{H}_{2} \mathrm{O}, 0.05 \mathrm{~g}$ of $\mathrm{CaCl}_{2}$, and $4 \mathrm{mg}$ of Vitamin $\mathrm{B}_{1}$. Mineral salt medium contained (per liter of distilled water) $4.0 \mathrm{~g}$ of $\mathrm{KH}_{2} \mathrm{PO}_{4}, 1.0 \mathrm{~g}$ of $\mathrm{MgSO}_{4} \cdot 7 \mathrm{H}_{2} \mathrm{O}, 0.05 \mathrm{~g}$ of $\mathrm{CaCl}_{2}$, and $4 \mathrm{mg}$ of Vitamin $\mathrm{B}_{1}$. The above culture media were adjusted to about $\mathrm{pH} 4.5$.

Biodegradation of Oil Shale. $2 \mathrm{~g}$ of oil shale sample was added into $100 \mathrm{~mL}$ of different culture medium for degradation. The spore suspension $\left(10^{7}\right.$ spores $\left.\cdot \mathrm{mL}^{-1}\right)$ of $P$. chrysosporium was inoculated into the medium and shaken at $150 \mathrm{r} \cdot \mathrm{m}^{-1}$ and $30^{\circ} \mathrm{C}$. The degradation time was set for $10,15,20$ and 30 $\mathrm{d}$. The culture medium of $P$. chrysosporium without oil shale was taken as the control. The experiment was carried out three repetitions.

After the oil shale samples were degraded by $P$. chrysosporium, the degradation solutions were centrifuged and filtered. Then the yellow supernatants (about $\mathrm{pH}$ 5.0) were adjusted to $\mathrm{pH} 12$ using strong $\mathrm{NaOH}$ solution. A large amount of flocculent precipitate appeared in the supernatants. After filtering and drying, the light yellow degradation products were obtained.

$$
\eta=\left(\mathrm{M}_{1}-\mathrm{M}_{2}\right) / \mathrm{M}_{0} \times 100 \%
$$

where $\eta$ was the degradation rate of oil shale; $M_{1}$ was the mass of the degradation product; $\mathbf{M}_{2}$ was the mass of the control product; $\mathrm{M}_{0}$ was the initial mass of oil shale.

Analysis of Degradation Products. XRD analysis of oil shale before and after $\mathrm{HNO}_{3}$ treatment, and oil shale residues after biodegradation was performed on a PW3040/ 60 X-ray diffractometer. The degradation products, oil shale before and after $\mathrm{HNO}_{3}$ treatment, and degradation residues after biodegradation were analyzed using Spectrum One Fourier Transform Infrared Spectrom (FT-IR).

\section{Results and Discussion}

Effect of Degradation Time and Temperature. The biodegradation rate of $P$. chrysosporium on oil shale increased with the degradation time at different temperature (Fig. 1). At $32 \circ \mathrm{C}$, the biodegradation rate reached $11.9 \%$ for $15 \mathrm{~d}$, and then increased slowly. Thus, the appropriate degradation time and temperature of $15 \mathrm{~d}$ and $32^{\circ} \mathrm{C}$ were selected. The selected temperature may be associated with lignin peroxidases of $P$. chrysosporium that control the degradation of organic macromolecules. The key enzymes in $P$. chrysosporium began to be produced at the end of their growth, and over $35^{\circ} \mathrm{C}$ could inactivate the enzymes. This reflected that the optimal degradation temperature $\left(32^{\circ} \mathrm{C}\right)$ is below the optimal growth temperature $\left(35^{\circ} \mathrm{C}\right)$.

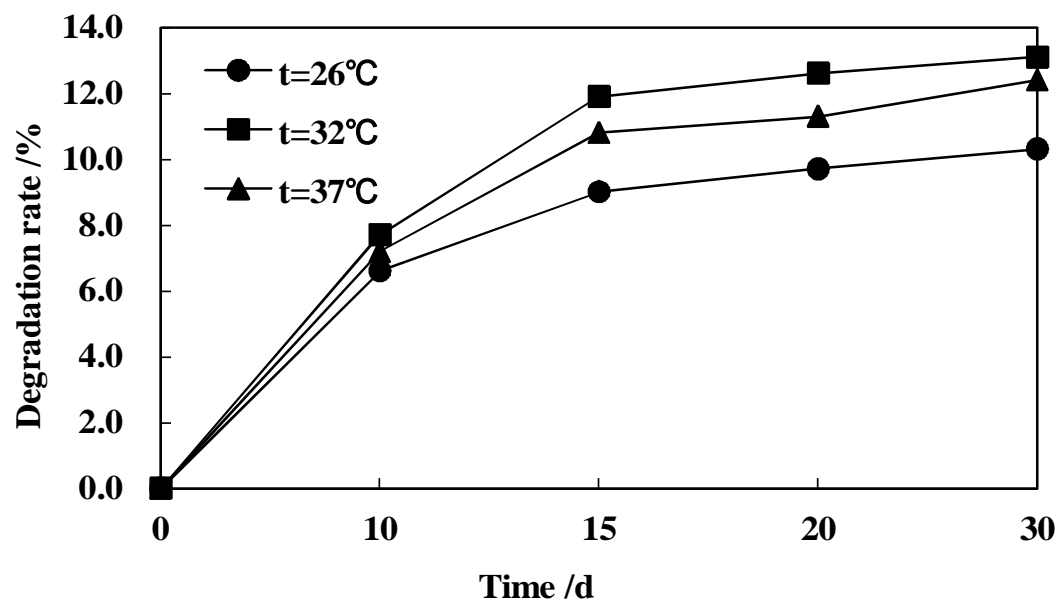

Fig.1 Effect of temperature and time on oil shale degradation by P. chrysosporium 
Effect of Carbon/nitrogen Ratio (C/N Ratio). High C/N ratio of nitrogen-limited medium for the degradation of oil shale was optimal, followed by potatodextrose medium, low $\mathrm{C} / \mathrm{N}$ ratio of carbon-limited medium, and mineral salt medium without $\mathrm{C}$ and $\mathrm{N}$ (Fig. 2). This showed high $\mathrm{C} / \mathrm{N}$ ratio in the medium was conductive to the degradation of oil shale. The activity of lignin peroxidases in $P$. chrysosporium was regulated by the external nutrient such as carbon, nitrogen and sulfur. It was reported that high $\mathrm{C} / \mathrm{N}$ ratio in the medium with shaking culture was in favor of the production and activity of the enzymes in $P$. chrysosporium [8].

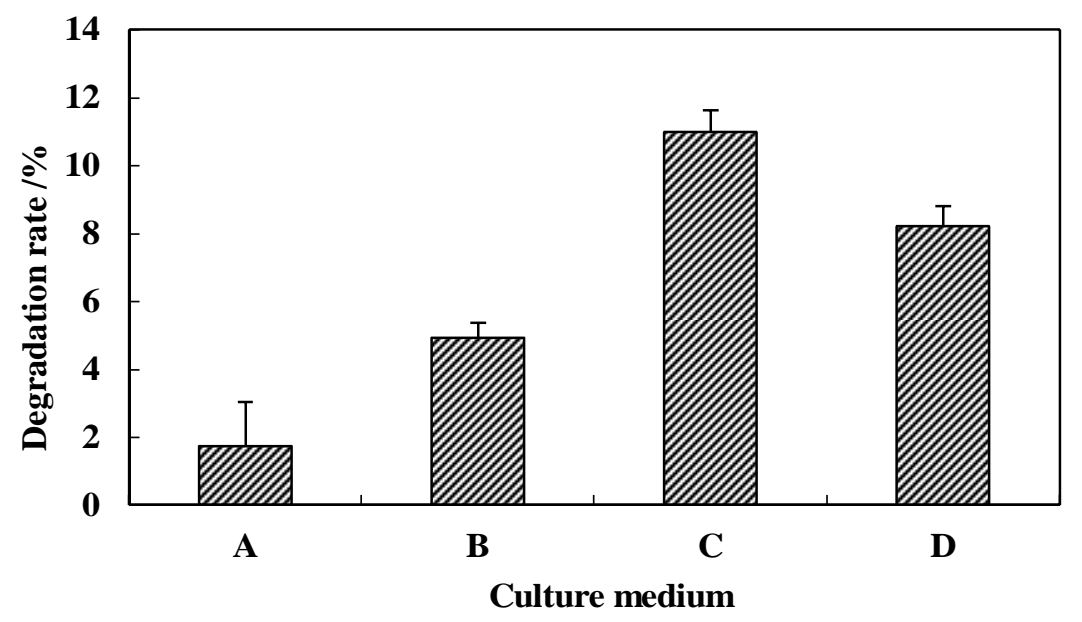

Fig. 2 Effect of culture media on oil shale degradation by $P$. chrysosporium

A: Mineral salt medium, B: carbon- limited medium, C: nitrogen-limited medium, D: potatodextrose medium

XRD Analysis of Degradation Products. The mineral components of oil shale before and after $\mathrm{HNO}_{3}$ treatment, and degradation residues changed obviously (Fig. 3). Before $\mathrm{HNO}_{3}$ treatment, oil shale mainly contained quartz, sillimanite, pyrite, siderite and kaolinite, etc. After $\mathrm{HNO}_{3}$ treatment, the peak at about $32^{\circ}$ in the XRD pattern disappeared, indicating that iron ore in the oil shale was almost removed, and a large amount of quartz and a few of kaolinite were remained. The peak of degradation residues was similar to that of oil shale after $\mathrm{HNO}_{3}$ treatment, but its peak at about $12^{\circ}$ disappeared, indicating that its structure may be transformed from kaolinite to nepheline, and quartz content significantly decreased. Thus, the $\mathrm{HNO}_{3}$ treatment could contribute to the removal of iron and other metal elements in oil shale, reduced the inhibitory effect of heavy metals on $P$. chrysosporium, and improved the biodegradation rate of oil shale. The result also indicated that a part of silicate in oil shale after $\mathrm{HNO}_{3}$ treatment was degraded by $P$. chrysosporium.

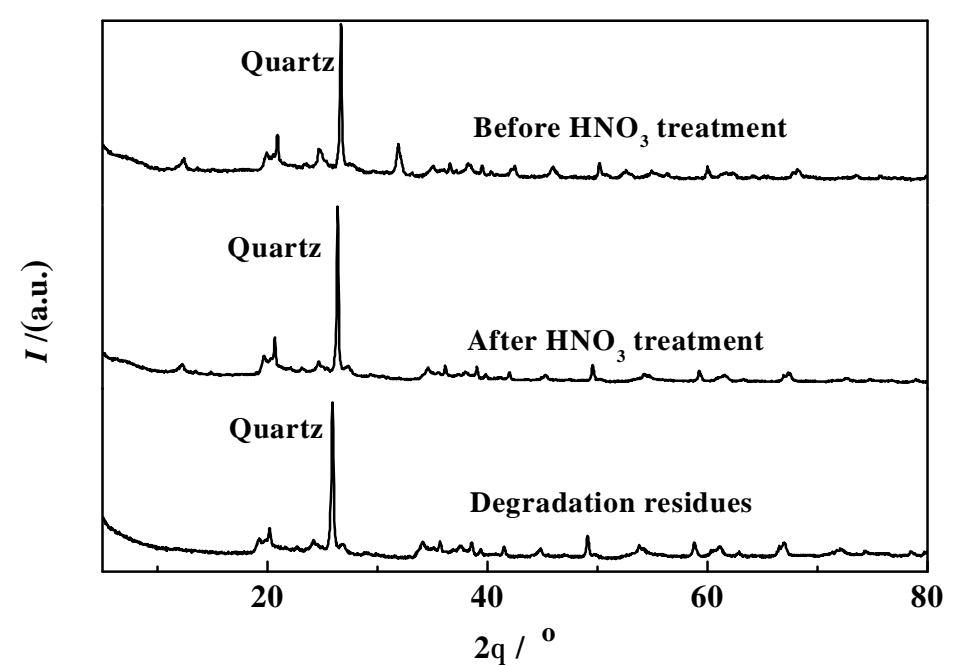

Fig. 3 XRD patterns of oil shale before and after $\mathrm{HNO}_{3}$ treatment and degradation residues 
FT-IR Analysis of Degradation Products. The infrared spectra of oil shale before and after $\mathrm{HNO}_{3}$ treatment, and degradation residues were similar (Fig. 4). There was a strongest peak of Si-O bond stretching vibration between 1116 and $1000 \mathrm{~cm}^{-1}$, caused by the overlapping of absorb bands of quartz and kaolinite in oil shale. The peaks at 2930 and $2850 \mathrm{~cm}^{-1}$ belonged to the characteristic absorption peaks of aliphatic hydrocarbons. A weak peak at $1637 \mathrm{~cm}^{-1}$ belonged to the skeletal vibration of aromatic ring. This showed that $\mathrm{SiO}_{2}$ could not be totally removed from oil shale by $\mathrm{HNO}_{3}$ treatment and $P$. chrysosporium, consistent with the XRD result.

But the infrared spectrum of the degradation product was obviously different from other spectra (Fig. 4). A wide and strong peak between 3000 and $3700 \mathrm{~cm}^{-1}$ was assigned to O-H stretching vibration. Another wide and strong peak at $1456 \mathrm{~cm}^{-1}$ was assigned to $-\mathrm{CH}_{2}$ stretching vibration. Two shoulder peaks at 1656 and $1560 \mathrm{~cm}^{-1}$ belonged to aromatic hydrocarbons. A weak peak at $1050 \mathrm{~cm}^{-1}$ was assigned to phenols or ethers. It indicated that the degradation products contained aromatic hydrocarbons, aliphatic hydrocarbons and their derivatives.

Compared with the peaks of oil shale before and after $\mathrm{HNO}_{3}$ treatment and degradation residues, the aromatic hydrocarbon peak of degradation products was significantly stronger than that of aliphatic hydrocarbons. This indicated that the main products were aromatic hydrocarbons, inconsistent with the report that the primary pyrolysis products of oil shale were aliphatic hydrocarbons [9]. It also indicated that the degradation of $P$. chrysosporium on oil shale was more conductive to the production of aromatic hydrocarbons.

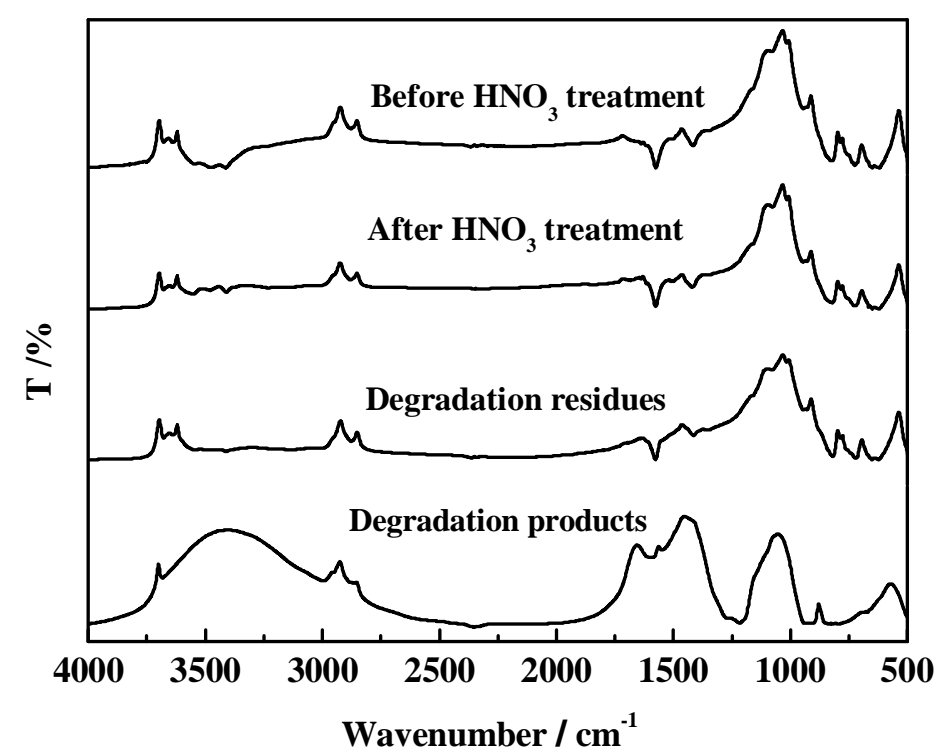

Fig. 4 FT-IR spectra of oil shale before and after $\mathrm{HNO}_{3}$ treatment, degradation residues, and degradation products

\section{Conclusions}

(1) P. chrysosporium showed the ability of degradation of oil shale through the XRD and FT-IR analysis.

(2) $15 \mathrm{~d}$ of degradation time, high carbon-nitrogen ratio of culture medium, and $32^{\circ} \mathrm{C}$ of degradation temperature did favor for the effect of oil shale degradation.

(3) Aromatic hydrocarbons were the main degradation products of oil shale by $P$. chrysosporium.

\section{Acknowledgements}

This work was financially supported by the National Natural Science Foundation of China (Grant No. 51204055), the Fundamental Research Funds for the Central Universities (N130420002). 


\section{References}

[1] B. Datangel and J.L. Goldfarb: Energ. Fuel Vol. 25 (2011), p. 3522

[2] F. Anjum, M. Shahid and A. Akcil: Hydrometallurgy Vol. 117-118 (2012), p.1

[3] A. Permanyer, J.L.R. Gallego and M.A. Caja: Petrol. Geol. Vol. 33 (2010), p.123

[4] R. Matlakowska and A. Sklodowska: J. Appl. Microbiol. Vol. 107 (2009), p. 858

[5] R. Matlakowska, W. Narkiewicz and A. Sklodowska: Environ. Sci. Technol. Vol. 44 (2010), p. 2433

[6] M.S.Y. Haddadin, A.A.A. Arqoub and I.A. Reesh: Energ. Convers. Manage. Vol. 50 (2009), p. 983

[7] M. Wengel, E. Kothe and C.M. Schmidt: Sci. Total Environ. Vol. 367 (2006), p. 383

[8] T.K. Keyser and J.G. Zeikus: J. Bacteriology Vol. 135 (1998), p. 790

[9] F.F. Xie, Z. Wang and L.W. Song: Spectroscopy and spectral analysis (In Chinese) Vol. 31 (2011), p. 91 